\title{
Docência e ensino remoto emergencial: das regulamentações à sala de aula virtual no IFCE
}

\section{Emergency remote teaching and teaching: from the regulations to the virtual classroom at IFCE}

\author{
Willana Nogueira Medeiros Galvão ${ }^{1}$ \\ Brena Samyly Sampaio de Paula ${ }^{2}$
}

\begin{abstract}
Resumo
O objetivo desse estudo é analisar os desafios impostos pelo ensino remoto para o desenvolvimento do processo de ensino e aprendizagem no Instituto Federal de Educação, Ciência e Tecnologia do Ceará (IFCE). Para tanto, examinou-se os textos normativos da instituição referente a essa temática, assim como, os questionários de avaliação do ensino remoto aplicados com estudantes de dois cursos de licenciatura. Diante do exposto, observou-se que, os pontos positivos são: a empatia e esforço dos professores, a flexibilização das aulas e a distribuição de chips para o acesso à internet. Como principais desafios estão o acesso à internet e o excesso de atividades. Os resultados fornecem pistas e impulsionam novos questionamentos que ajudam a pensar sobre o futuro do ensino remoto.
\end{abstract}

Palavras-chave: Pandemia; Prática docente; Ensino remoto; Normativos

\begin{abstract}
The purpose of this study is to investigate the challenges imposed by remote education for the development of the teaching and learning process at IFCE. To this end, the institution's regulations on this issue and the questionnaires for the evaluation of remote education with students were analyzed. It was observed that the positive points are: the empathy and effort of the teachers, the flexibility of the classes and the distribution of chips for internet access. The main challenges are quality access and excessive activities. The results provide clues and drive new questions that inform about the future of remote education.
\end{abstract}

Keywords: Pandemic; Teaching practice; Remote teaching; Normative

1 Doutoranda em Educação pela Universidade Estadual do Ceará (UECE). Professora do Instituto Federal de Educação, Ciência e Tecnologia do Ceará (IFCE). Coordenadora do Grupo de Pesquisa Formação de Professores, Política Educacional e Desigualdade Social. E-mail: willana.nogueira@ifce.edu.br https://orcid.org/0000-0002-1136-0648

2 Mestranda em Educação pela Universidade Federal do Ceará (UECE). Professora do Instituto Federal de Educação, Ciência e Tecnologia do Ceará (IFCE). Integrante do Grupo de Pesquisa Formação de Professores, Política Educacional e Desigualdade Social. E-mail: brena.sampaio@ifce.edu.br https://orcid.org/0000-0002-1538-3927 


\section{REVISTA DE ADMINISTRAÇÃO EDUCACIONAL}

ISSN -2359-1382

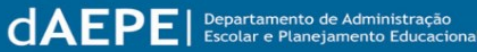

\section{Introdução}

O ano de 2020 foi marcado por uma pandemia que atingiu o mundo e o Brasil. Notícias relacionadas ao aparecimento de um novo coronavírus descoberto inicialmente em Wuhan, na China, circularam em diversos veículos de comunicação. A velocidade da divulgação dessa informação inesperada, logo no início do ano vigente, trouxe imensos impactos à vida da população mundial. Em virtude do elevado poder de contaminação, rapidamente foram identificados casos em diversos países, e assim, no dia 30 de janeiro de 2020, a Organização Mundial da Saúde (OMS), declarou esse surto como uma Emergência de Saúde Pública de Importância Internacional (ESPII).

No Brasil, até o mês de março de 2021, 12.490 .362 pessoas foram infectadas com o vírus e 310.550 vidas foram perdidas. Os primeiros casos registrados no país datam do mês de março. No Ceará, os primeiros casos de infectados foram identificados no dia 15 do mês em questão. Esse cenário impulsionou a promulgação do Decreto Estadual № 33.510 , de 16 de março de 2020 que determinou situação de emergência em saúde, e dispôs diversas medidas para o enfrentamento e contenção do novo coronavírus, dentre elas, a suspensão de eventos com mais de cem pessoas e a suspensão das aulas presenciais. Dois meses depois na capital, com o avanço no número de casos, foi instituído o Decreto 33.574 de 05 de maio de 2020, que determinou o isolamento social rígido como medida de enfrentamento a pandemia. Por conta disso, comércio e instituições não essenciais foram fechadas.

A mudança repentina na rotina da sociedade e, ações que não tiveram o tempo adequado para serem planejadas, exigiram de vários setores novas posturas, e, com a educação não poderia ser diferente. Com o intuito de adaptar a rotina organizacional ao cenário de isolamento social, novos caminhos tiveram que ser traçados e dessa forma, as aulas presenciais foram substituídas pelo ensino remoto. Esse processo de transição exigiu dos diversos atores escolares, gestão, docentes, estudantes e familiares, uma série de adaptações de modo que a estratégia adotada tivesse sustentação. Nesse contexto,

O uso de novas estratégias pedagógicas trouxe desafios, como capacitação docente, adaptação dos estudantes, saúde mental da comunidade e manejo do tempo para estudo, e a garantia de acesso por 


\section{REVISTA DE ADMINISTRAÇÃO EDUCACIONAL}

parte dos estudantes tornou-se uma preocupação da comunidade acadêmica (APPENZELLER et al, 2020, p. 02)

No Instituto Federal do Ceará (IFCE), foco deste estudo, as aulas foram suspensas no dia 16 de março. Quatro dias depois, por meio da Portaria No 737/PROGEP/IFCE de 20 de março de 2020, foi instituído o regime de trabalho remoto para a realização de atividades que estivessem relacionadas com o exercício de competência do IFCE, deixando explícito o caráter temporário e excepcional dessa determinação.

Neste primeiro momento, o calendário seguiu suspenso com atividades extracurriculares à distância, sendo retomado com aulas remotas em junho de 2020, amparado pela Resolução $\mathrm{N}^{\circ} 11$. Ao longo desse percurso, diversas dúvidas caminharam e caminham em paralelo a esse processo: quanto tempo o ensino remoto vai durar? Como garantir o acesso remoto a todos os estudantes e em todas as localidades? Como adaptar as aulas ao meio digital? Como garantir o aprendizado dos estudantes? Como combater a evasão? Dentre outros.

Assim, a presente pesquisa se propõe a investigar: como a instituição foco do estudo respondeu aos desafios impostos pela COVID-19 para o ensino? O que dizem os documentos que regulamentam o ensino remoto emergencial? Qual a percepção dos estudantes acerca da vivência do ensino remoto? Quais são as principais dificuldades enfrentadas pelos estudantes diante dessa modalidade de ensino? Nesse contexto o objetivo do artigo é investigar os desafios impostos pelo ensino remoto para o desenvolvimento do processo de ensino e aprendizagem em dois cursos de licenciatura de um campus localizado no interior do Ceará.

Para tanto, serão analisados normativos publicados pela instituição entre os meses de março e setembro de 2020 que tratam dessa questão. O estudo se apoia ainda nos questionários de avaliação do ensino remoto aplicado com os estudantes de nove turmas no final do semestre 2020.1, que na instituição em questão ocorreu no final do mês de setembro.

Assim, partindo de uma abordagem qualitativa e utilizando como técnica principal de coleta de dados a pesquisa documental em fontes de dados primários (GIL. 2008), o presente estudo se apoia no estudo de caso como método, pelo fato de se tentar esclarecer 


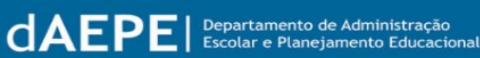

"uma decisão ou um conjunto de decisões: o motivo pelo qual foram tomadas, como foram implementadas e com qual resultado" (YIN, 2005, p. 31).

Para coleta e organização do processo seguiu-se quatro passos: 1. Mapeamento dos normativos relacionados ao ensino no período pandêmico; 2. Análise das principais mudanças propostas pelos normativos com base no Regulamento da Organização Didática (ROD). 3. Análise dos questionários de avaliação do ensino remoto, aplicados a estudantes de 9 turmas. 4. Considerações sobre os achados à luz da fundamentação teórica que ampara o tema.

Importante informar que os questionários foram aplicados de forma online e não contam com a identificação dos estudantes que responderam. O seu preenchimento não foi de caráter obrigatório e sua realização ocorreu no encerramento das disciplinas do semestre 2020.1, em setembro de 2020, em função do processo de avaliação do planejamento e execução das disciplinas cursadas. O questionário contava com perguntas sobre os pontos positivos, negativos e pedia sugestões para a realização da disciplina de forma remota no semestre seguinte.

\section{O ensino remoto e seus normativos}

No âmbito da educação, um dos maiores desafios no contexto da pandemia foi repensar e adaptar a prática pedagógica presencial para as práticas de ensino remoto emergencial por conta da inviabilidade do contato físico nas escolas e instituições de ensino superior. A pressão pela retomada das atividades nas escolas e universidades fez com que essas instituições agissem de forma rápida, sem muito tempo para se organizarem, articularem e planejarem as estratégias pedagógicas. Em relação às orientações oficiais, o que se percebe, na visão de Santos, Lima e Sousa (2020, p.1636), é que de uma maneira geral, podemos observar:

[...] soluções idealizadas e implementadas na lógica tão conhecida e ineficaz da pressa, do improviso, da superficialidade e da reificação das desigualdades sociais, econômicas e educacionais. As saídas encontradas expressam, portanto, uma tentativa de mudança na continuidade. Reproduzem-se e se agravam os problemas a partir de um argumento, enunciado por empresários da educação e setores do governo - de que "afinal precisamos fazer alguma coisa, pois não será agora que iremos resolver o problema da equidade". 
Diante da imprevisibilidade do cenário e na busca de dirimir os prejuízos nos calendários letivos e, principalmente, na aprendizagem dos estudantes, o Ministério da Educação autorizou, por meio da Portaria $N^{0} 343$, de 17 de março 2020, que as aulas presenciais fossem substituídas por aulas em meios digitais durante o tempo que durar a pandemia. Contudo, o contexto anômalo e a demanda cada vez maior pelo uso das tecnologias digitais fizeram emergir na área uma compreensão equivocada de que ensino remoto é a mesma coisa que Educação à Distância.

Em virtude do exposto, cabe aqui uma breve explanação sobre as especificidades dos referidos termos. Primeiramente, vamos nos debruçar sobre a compreensão de Educação a Distância, modalidade alternativa ao presencial, que de acordo com as Diretrizes Curriculares Nacionais da Educação Básica (2013), tem como característica a mediação didático-pedagógica por meio das tecnologias de informação e comunicação, de forma que professores e estudantes possam desenvolver as atividades educativas, em diferentes espaços e tempos. Para tanto, essa metodologia está alicerçada em uma legislação específica e pode ser desenvolvida em todos os níveis e modalidades de ensino.

O segundo termo, conforme exposto anteriormente, ganhou destaque por conta da pandemia do coronavírus. Até então, não havia nenhuma menção na legislação que regulamenta a educação brasileira sobre ensino remoto emergencial. Para nos ajudar a compreender esse fenômeno, Behar (2020) recorre ao sentido das palavras que compõem a expressão: "remoto" está diretamente ligada à compreensão de distanciamento geográfico. Por conta disso, o ensino recebe esse adjetivo tendo em vista o impedimento, estabelecido por decreto, de professores e estudantes frequentarem presencialmente as escolas. Por outro lado, configura-se como "emergencial" porque todo o planejamento pedagógico previsto para esse ano precisou ser reconfigurado, tendo em vista que os currículos de muitas instituições não foram idealizados para o trabalho remoto, mas sim presencial.

Corroborando com essa questão, Appenzeller et al (2020, p. 5) explica que

É importante ressaltar que o ensino remoto emergencial apresenta diferenças fundamentais dos modelos de ensino a distância ou modelo híbrido que têm um planejamento prévio de conteúdo e tempo cuidadoso usando modelos de desenvolvimento e planejamento bem conhecidos. $\mathrm{O}$ 


\section{REVISTA DE ADMINISTRAÇÃO EDUCACIONAL}

entendimento dessas diferenças é fundamental para reduzir a ansiedade por parte dos docentes, que não se sentem preparados para ministrar aulas não presenciais, e dos discentes.

Para exemplificar como a modalidade de ensino remoto tem se dado no contexto do nível superior, é importante compreender o percurso realizado pela instituição foco do presente estudo, desde a suspensão do calendário até a execução do ensino à distância de caráter emergencial. O IFCE foi criado nos termos da Lei. $\mathrm{N}^{\circ} 11.892$, de 29 de dezembro de 2008, a partir da integração do Centro Federal de Educação Tecnológica do Ceará com as Escolas Agrotécnicas Federais de Crato e de Iguatu, vinculado ao MEC. A instituição é de natureza jurídica, possuindo autonomia administrativa, patrimonial, financeira, didáticopedagógica e disciplinar. No que se refere à incidência das disposições que regem a regulação, avaliação e supervisão da instituição e dos cursos de educação superior, o IFCE é equiparado às universidades federais.

A instituição conta, além da reitoria e do polo de inovação, com 32 campis ativos e um em construção. O IFCE, revela assim, seu importante papel no processo de interiorização e democratização do acesso à educação superior e técnica pública, conforme revela a figura 1.

Figura 1- Distribuição geográfica dos campis do IFCE
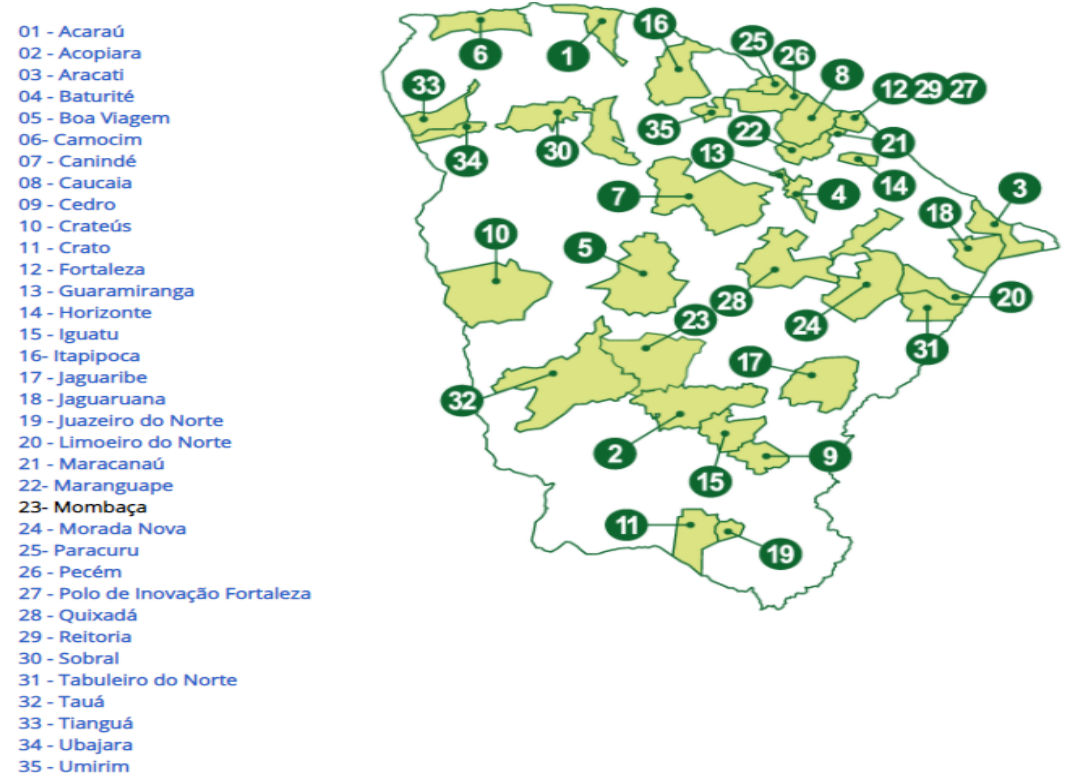

Fonte: https://ifce.edu.br/acesso-rapido/campi/campi

Revista Administração Educacional - CE - UFPE Recife-PE, V.12 N. 1 p. 53-71, jan./jun. 2021

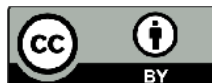




\section{REVISTA DE ADMINISTRAÇÃO EDUCACIONAL}

O IFCE pode ofertar três tipos de cursos: formação inicial e continuada - FIC; técnicos (integrado, concomitantes ou subsequentes) e superiores (licenciatura, bacharelado, tecnológico e pós-graduação) ofertados em periodicidade anual ou semestral, exceto os FICs que podem ser ofertados conforme conveniência. Segundo o Portal IFCE em números, o Instituto contou com 35. 651 matrículas ativas no semestre 2020.1, distribuídas de acordo com as informações reveladas no quadro 1:

Quadro 1- Matrícula IFCE- 2020.1

\begin{tabular}{|c|c|c|c|}
\hline Natureza & Especificidade & Cursando & Curso \\
\hline $\begin{array}{c}\text { Qualificação } \\
\text { Profissional }\end{array}$ & FIC & 6.099 & 273 \\
\hline \multirow{3}{*}{ Técnico } & Concomitante & 1.883 & 29 \\
\cline { 2 - 4 } & Integrado & 5.340 & 49 \\
\cline { 2 - 4 } & Subsequente & 4.525 & 70 \\
\hline \multirow{3}{*}{ Graduação } & Bacharelado & 5.247 & 26 \\
\cline { 2 - 4 } & Licenciatura & 7.248 & 50 \\
\cline { 2 - 4 } & Tecnologia & 4.203 & 33 \\
\hline Pós-graduação & Lato sensu & 645 & 16 \\
\cline { 2 - 4 } & Strictu senso & 438 & 11 \\
\hline
\end{tabular}

Fonte: IFCE em números (https://ifceemnumeros.ifce.edu.br/matriculados/)

Nesse cenário institucional, com todos os desafios que se apresentam no contexto pandêmico no corrente ano, a instituição adotou o ensino remoto como estratégia para não paralisar suas atividades por tempo indeterminado. Para compreender como esse processo se deu, mapeou-se os normativos que foram publicados para a orientação das ações. Para tanto, recorreu-se ao portal Boletim de Serviços da instituição pesquisada. Conforme o quadro 2, é possível observar as determinações publicadas no período de suspensão do calendário.

Quadro 2- Normativos publicado após a suspensão do calendário letivo 


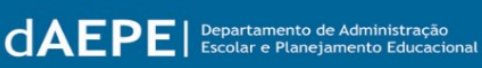

\begin{tabular}{|c|c|c|}
\hline Normativo & Data & Descrição \\
\hline $\begin{array}{l}\text { PORTARIA No } \\
\text { 316/GABR/REITORIA }\end{array}$ & $\begin{array}{l}16 \text { de março de } \\
2020\end{array}$ & $\begin{array}{l}\text { Suspensão das atividades acadêmicas presenciais até } \\
\qquad 20 \text { de março. }\end{array}$ \\
\hline $\begin{array}{l}\text { PORTARIA No } \\
\text { 318/GABR/REITORIA }\end{array}$ & $\begin{array}{l}16 \text { de março de } \\
2020\end{array}$ & $\begin{array}{l}\text { Instituído o Comitê de Enfrentamento (CEC/IFCE) ao } \\
\text { novo coronavirús. }\end{array}$ \\
\hline $\begin{array}{l}\text { Ofício-Circular no } \\
\text { 4/2020/PROEN/REITORIA- } \\
\text { IFCE }\end{array}$ & $\begin{array}{l}16 \text { de março de } \\
2020\end{array}$ & $\begin{array}{l}\text { Orientações referentes às atividades de ensino em } \\
\text { caráter excepcional. }\end{array}$ \\
\hline $\begin{array}{l}\text { PORTARIA No } \\
\text { 337/GABR/REITORIA }\end{array}$ & $\begin{array}{c}18 \text { de março de } \\
2020\end{array}$ & $\begin{array}{c}\text { Prorrogadas, até o dia } 3 \text { de abril de } 2020 \text {, a suspensão } \\
\text { das atividades acadêmicas presenciais. }\end{array}$ \\
\hline RESOLUÇÃO No 7 & $\begin{array}{c}20 \text { de março de } \\
2020\end{array}$ & $\begin{array}{c}\text { Aprova ad referendum a suspensão dos calendários } \\
\text { letivos de todos os campi. }\end{array}$ \\
\hline $\begin{array}{l}\text { Ofício Conjunto Circular no } \\
\text { 01/2020 PROEN/ } \\
\text { PROEXT/PRPI/REITORIA }\end{array}$ & $\begin{array}{c}24 \text { de março de } \\
2020\end{array}$ & $\begin{array}{l}\text { Desenvolvimento de atividades acadêmicas durante o } \\
\text { período de suspensão dos calendários letivos no } \\
\text { IFCE. }\end{array}$ \\
\hline RESOLUÇÃ̃ N $^{\circ} 8$ & $\begin{array}{l}03 \text { de abril de } \\
2020\end{array}$ & $\begin{array}{l}\text { Aprova ad referendum a suspensão dos calendários } \\
\text { letivos de todos os campi até } 30 \text { de abril. }\end{array}$ \\
\hline $\begin{array}{l}\text { Ofício-Circular no } \\
\text { 5/2020/PROEN/REITORIA- } \\
\text { IFCE }\end{array}$ & $\begin{array}{l}14 \text { de abril de } \\
2020\end{array}$ & $\begin{array}{l}\text { Orientações aos campi do IFCE com base na } \\
\text { Resolução } n^{\circ} 8 \text { de } 3 \text { de abril de } 2020 \text {. }\end{array}$ \\
\hline $\begin{array}{l}\text { Ofício-Circular no } \\
\text { 7/2020/PROEXT /REITORIA- } \\
\text { IFCE }\end{array}$ & $\begin{array}{l}17 \text { de abril de } \\
2020\end{array}$ & $\begin{array}{l}\text { Encaminhamento do Edital de Regulamentação para } \\
\text { Participação no Projeto FICemCASA. }\end{array}$ \\
\hline
\end{tabular}

Fonte: elaboração própria.

Os primeiros casos de COVID-19 registrados no Ceará datam do dia 15 de março de 2020. No dia seguinte, 16 de março do ano vigente, um Comitê de Enfrentamento ao COVID-19 foi instituído e as atividades de ensino presencial suspensas até o dia 20 de março. Os docentes, portanto, deveriam manter as aulas, a partir da elaboração de um Plano de Estudo para que os estudantes realizassem as atividades em suas residências. As atividades deveriam ser registradas no Sistema Acadêmico da instituição como meio para acompanhamento de frequência e notas. Nesse contexto, de forma mais específica, a presença do estudante ficaria condicionada à entrega das atividades.

Em 20 de março, 5 dias após a primeira determinação institucional, houve a 


\section{REVISTA DE ADMINISTRAÇÃO EDUCACIONAL}

suspensão do calendário acadêmico do dia 23 de março a 03 de abril. Com a suspensão das atividades curriculares, no dia 24 de março, um Ofício-circular foi elaborado, apresentando orientações em relação ao meio pelo qual, os docentes deveriam executar suas atividades neste período de suspensão.

O projeto FIC em Casa foi uma das estratégias adotadas. Regulamentado pelo Ofício-Circular $n^{\circ} 7$ instituído em abril, o projeto impulsionou professores de diversas áreas que propuseram cursos de extensão durante esse período, e assim, o calendário continuou suspenso até 31 de maio (Resolução 09). Neste período a Portaria 511, art.1 apresentou a seguinte resolução "Prorroga-se a suspensão das atividades acadêmicas e administrativas presenciais nos campi e reitoria, enquanto perdurar o estado de Emergência em Saúde Pública de Importância Internacional decorrente da COVID-19”. Essa determinação finaliza o processo de constante prorrogação da suspensão das atividades presenciais. Nesse período em questão, além do FIC em Casa, outras ações foram desenvolvidas, como palestras, minicursos e eventos relacionados aos cursos ofertados pela instituição.

Com relação ao calendário acadêmico, em 31 de maio a Resolução 011 aprova os procedimentos para que as aulas retornassem por meios remotos. Com isso, a partir de $1^{\circ}$ de junho de 2020, inicia-se de maneira gradativa a entrada dessa modalidade de ensino. Como forma de preparação para esse período, reuniões para planejamento, orientação e formação foram realizadas para que os docentes pudessem organizar suas aulas.

No quadro 3 é possível observar os normativos que amparam o processo de implementação do ensino remoto na instituição.

Quadro 3- Normativos para retomada do calendário letivo 
dAEPE|

\section{ISSN -2359-1382}

\begin{tabular}{|c|c|c|}
\hline Normativo & Data & Descrição \\
\hline Portaria $N^{\circ}$ 484/GABR/REITORIA & $\begin{array}{l}23 \text { de abril de } \\
2020\end{array}$ & $\begin{array}{l}\text { Criar a Comissão responsável pela elaboração do } \\
\text { Plano de Continuidade do Calendário Letivo. }\end{array}$ \\
\hline RESOLUÇÃO No 9 & $\begin{array}{l}01 \text { de maio de } \\
2020\end{array}$ & $\begin{array}{l}\text { Aprova ad referendum a suspensão dos } \\
\text { calendários letivos de todos os campi do } \\
\text { Instituto Federal de Educação, Ciência e } \\
\text { Tecnologia do Ceará (IFCE) e adota novas } \\
\text { providências. Período de } 2 \text { a } 31 / 05 \text {. }\end{array}$ \\
\hline Portaria $N^{0}$ 511/GABR/REITORIA & $\begin{array}{l}01 \text { de maio de } \\
2020\end{array}$ & $\begin{array}{l}\text { Reitoria prorroga a suspensão das atividades } \\
\text { acadêmicas e administrativas presenciais nos } \\
\text { campi e reitoria enquanto perdurar o estado de } \\
\text { Emergência em Saúde Pública. }\end{array}$ \\
\hline $\begin{array}{c}\text { Ofício-Circular no 6/2020/PROEN/ } \\
\text { REITORIA-IFCE }\end{array}$ & $\begin{array}{l}12 \text { de maio de } \\
2020\end{array}$ & $\begin{array}{l}\text { Implementação das atividades estabelecidas na } \\
\text { Resolução No 9, de } 10 \text { de maio de } 2020 .\end{array}$ \\
\hline $\begin{array}{c}\text { Ofício-Circular no 7/2020/PROEN/ } \\
\text { REITORIA-IFCE }\end{array}$ & $\begin{array}{l}21 \text { de maio de } \\
2020\end{array}$ & $\begin{array}{c}\text { Regras de convivência a serem aplicadas para o } \\
\text { ensino remoto. }\end{array}$ \\
\hline RESOLUÇÃO $\mathbf{N}^{\circ} 11$ & $\begin{array}{l}31 \text { de maio de } \\
2020\end{array}$ & $\begin{array}{l}\text { Aprova os procedimentos para o retorno às aulas } \\
\text { dos campi do Instituto Federal de Educação, } \\
\text { Ciência e Tecnologia do Ceará (IFCE), de forma } \\
\text { remota e gradativa, e adota novas providências. }\end{array}$ \\
\hline $\begin{array}{c}\text { Ofício Conjunto Circular no } 3 / 2020 \\
\text { PROEN/PROEXT/ } \\
\text { PRPI/REITORIA }\end{array}$ & $\begin{array}{l}01 \text { de junho de } \\
2020\end{array}$ & $\begin{array}{l}\text { Ações a serem executadas pelos campi para } \\
\text { retorno às aulas de forma remota e gradativa. }\end{array}$ \\
\hline $\begin{array}{l}\text { Ofício-Circular no 9/2020/PROEN/ } \\
\text { REITORIA-IFCE }\end{array}$ & $\begin{array}{l}01 \text { de junho } \\
2020\end{array}$ & $\begin{array}{l}\text { Procedimentos dos concludentes para assinatura } \\
\text { da Ata de colação de grau especial. }\end{array}$ \\
\hline $\begin{array}{l}\text { Ofício-Circular no 10/2020/PROEN/ } \\
\text { REITORIA-IFCE }\end{array}$ & $\begin{array}{l}9 \text { de junho de } \\
2020\end{array}$ & $\begin{array}{l}\text { Procedimentos a serem realizados no Sistema } \\
\text { Acadêmico a partir do início das aulas remotas } \\
\text { nos campi. }\end{array}$ \\
\hline $\begin{array}{l}\text { Ofício Conjunto Circular no 4/2020 } \\
\text { PROEN/PROEXT/PRPI/REITORIA }\end{array}$ & $\begin{array}{l}25 \text { de junho de } \\
2020 \text {. }\end{array}$ & $\begin{array}{l}\text { Apresenta as ações referentes ao } \\
\text { desenvolvimento de práticas profissionais de } \\
\text { estágio e de laboratórios especializados, na } \\
\text { forma remota, a serem executadas pelos campi, } \\
\text { visando atender ao estabelecido na Resolução no } \\
\text { 15, de } 07 \text { de julho de } 2020 \text {, que "Altera o art. } 10 \\
\text { da Resolução No } 11 \text {, de } 31 \text { de maio de } 2020 \text {. }\end{array}$ \\
\hline $\begin{array}{c}\text { PORTARIA No } \\
\text { 706/GABR/REITORIA }\end{array}$ & $\begin{array}{l}26 \text { de junho de } \\
2020\end{array}$ & $\begin{array}{l}\text { Critérios de elegibilidade necessários para o } \\
\text { recebimento do SIM Card Chip. }\end{array}$ \\
\hline
\end{tabular}




\section{REVISTA DE ADMINISTRAÇÃO EDUCACIONAL}

\section{ISSN -2359-1382}

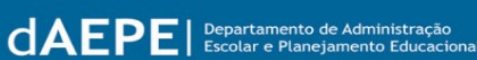

\begin{tabular}{|l|l|c|} 
RESOLUÇÃO N $\mathbf{N}^{\mathbf{0}} \mathbf{1 5}$ & $\begin{array}{c}07 \text { de julho de } \\
2020\end{array}$ & $\begin{array}{c}\text { Altera o artigo 1o da Resolução No 11, de 31 de } \\
\text { maio de 2020, que aprova os procedimentos para } \\
\text { o retorno às aulas dos campi do Instituto Federal } \\
\text { de Educação, Ciência e Tecnologia do Ceará } \\
\text { (IFCE), de forma remota e gradativa, e adota } \\
\text { novas providências. }\end{array}$ \\
\hline
\end{tabular}

Fonte: elaboração própria.

A instituição elegeu as ferramentas do G-Suíte, Google Classroom e o Google Meet, como dispositivos oficiais para a realização do ensino remoto. É importante salientar, que os códigos de cada sala de aula deveriam ser encaminhados para a Reitoria para que desse modo a "instituição possa ter uma visão sistêmica do processo" (Ofício-Circular no 5), que são direcionados aos estudantes.

Para resguardar o direito de imagem dos estudantes e dos professores, regras de convivência foram determinadas pela Pró-Reitora de Ensino, conforme Ofício-Circular 07. As regras do ROD foram resguardadas também para o ambiente remoto.

As aulas deveriam ser ministradas de forma síncrona e assíncrona. Definiu-se a necessidade de elaboração de pelo menos, uma atividade para cada semana com a finalidade de contabilizar como frequência. Algumas destas atividades também poderiam ser avaliativas, com o intuito de aferir as notas dos estudantes, conforme Ofício-Circular $\mathrm{n}^{\circ}$ $5,8.1 \mathrm{~g}$.

Com relação à oferta de cursos EAD, os art. 12 e 13 do ROD abrem o precedente para $20 \%$ nos cursos presenciais ou a oferta integral, atentando-se para a legislação pertinente; o suporte tecnológico necessário incluindo o polo de apoio presencial para os cursos integralmente em EAD; acompanhamento de docentes; editais específicos ou contemplação no PPC, no caso dos presenciais.

Um ponto interessante, abordado no ROD está no artigo 11 e artigo 14, parágrafo único, que preconizam as seguintes medidas: "as matrizes curriculares dos cursos deverão estimular o mínimo de pré-requisitos possível, permitindo a flexibilidade no itinerário formativo do estudante" (IFCE. 2015, p.8). Vale ressaltar que esta questão é importante na garantia de uma maior flexibilidade da gestão acadêmica, em especial, em situações emergenciais como a vivenciada nesta pandemia. 


\title{
REVISTA DE ADMINISTRAÇÃO EDUCACIONAL
}

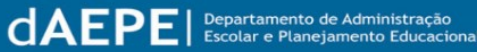

Respeitando o art. 33 do ROD, que obriga "o cumprimento da carga horária e de todo o conteúdo programático", o ensino remoto exigiu uma flexibilização da distribuição da carga horária do curso em termos de dias letivos. Apesar dos benefícios possibilitados pelo uso dessa estratégia, como por exemplo, a garantia do contato, ainda que precário, entre as instituições educacionais e os estudantes, uma vez que sem o ensino remoto, os estudantes estariam todos esses meses com as atividades acadêmicas paralisadas, observase também, inúmeras outras dificuldades que foram surgindo com o passar dos dias decorrentes desse novo cenário educacional.

Entre elas, está relacionada aos discentes. Com as mudanças provocadas pela pandemia, a questão dos direitos dos estudantes têm sido um assunto bastante sensível, pois alguns dos direitos previstos no ROD são resguardados dentro do possível, como receber assistência de saúde (art. 173. VI), o recebimento de alimentação saudável (art. 173. VIII), atividades que se adaptaram ao novo cenário, principalmente por meio do atendimento psicológico e da distribuição da merenda escolar. No entanto, aspectos relacionados à qualidade no ensino (art. 173. I), que requerem uma estrutura básica para o aprendizado (art. 173. II) se materializam como um desafio para a instituição.

No próximo tópico é explanado reflexões acerca de como esse processo tem se concretizado na prática, nas salas de aula virtual com todas as suas dificuldades e potencialidades.

\section{As dificuldades discentes em cenário de sala de aula virtual}

Segundo Appenzeller et al (2020, p. 05) o ensino remoto emergencial é caracterizado

\begin{abstract}
Pela mudança temporária do ensino presencial para o ensino remoto. $\mathrm{O}$ ensino passa, em um momento de crise, como no caso da pandemia da Sars-CoV-2, para totalmente remoto, e todas as orientações e todo o conteúdo educacional são ministrados em plataformas a distância. O objetivo educacional não é criar um curso a distância robusto, mas fornecer acesso temporário à instrução e apoio instrucional de uma maneira que seja rápida de configurar e que esteja disponível de forma confiável durante o período.
\end{abstract}

Para análise de como o processo descrito tem chegado até os estudantes e 


\section{REVISTA DE ADMINISTRAÇÃO EDUCACIONAL}

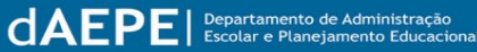

professores de um campi do IFCE no interior do Ceará, nos debruçamos sob 9 turmas matriculadas nas seguintes disciplinas: Fundamentos Filosóficos e Sociológicos da Educação, Política Educacional, Didática, Psicologia do Desenvolvimento, Currículos e Programas, Estágio Supervisionado de Observação no Ensino Fundamental, Estágio Supervisionado de Regência no Ensino Fundamental, vinculadas aos cursos de Física e Letras Português/ Inglês da presente instituição.

Para realização das aulas assíncronas das disciplinas em questão, o Google Classroom foi definido como plataforma principal. Para tanto, os docentes organizaram o espaço de modo que houvesse os seguintes tópicos:

- Dúvidas e comentários;

- Biblioteca da disciplina;

- Mídias de apoio;

- Gravação das aulas síncronas;

- Atividades semanais.

Para a realização das aulas síncronas a instituição determinou o uso do Google Meet. O link para acesso é disponibilizado antes da aula no Google Classroom. A ferramenta acaba funcionando como um canal direto de comunicação, os docentes podem esclarecer dúvidas dos estudantes, apresentar a aula e estabelecer um diálogo mais próximo do que acontece na sala de aula presencial.

No mês de setembro de 2020, no final do semestre 2020.1, um questionário foi aplicado com as turmas indicadas anteriormente. Não havia obrigatoriedade de respostas e nem os estudantes eram identificados, para tanto, houve a possibilidade de se expressarem livremente para que desse modo, fosse possível o processo corresponder aos trâmites éticos.

Sobre os pontos positivos avaliados pelos estudantes durante a parte do semestre realizado de forma remota estão:

1) O esforço e empatia dos professores. Importante destacar em relação a esse aspecto, que embora os professores estejam conduzindo o processo com dedicação, esbarraram, principalmente no início, com as dificuldades de compreensão das ferramentas e da sua aplicação para realização do ensino. Ainda que a instituição tenha realizado cursos de introdução a essa utilização, estas foram breves e, 


\section{REVISTA DE ADMINISTRAÇÃO EDUCACIONAL}

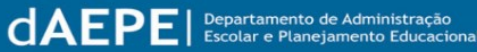

portanto, não se configuram como recurso suficiente para professores que pertencem a uma geração que não é nativa digital.

2) A flexibilidade que a divisão entre aulas síncronas e assíncronas possibilitam. Percebe-se que a possibilidade de estabelecer o melhor horário para estudo (no caso das aulas assíncronas) e o acompanhamento das aulas síncronas, esteja ocorrendo no horário de aula normal. Vale ressaltar ainda que, a gravação da aula é posteriormente disponibilizada para a turma após o término da aula, ou seja, mais um ponto que colabora para que os estudantes possam cursar de forma mais tranquila as suas licenciaturas.

Ressalta-se, portanto, que o ensino remoto trouxe sérios desafios para os professores, estudantes e famílias afetadas pela pandemia. Vale expor ainda os diversos docentes que não estavam preparados para o trabalho com plataformas digitais, e de igual modo, os docentes e discentes que precisavam de mais tempo para a adaptação dessa nova fase experimentada pela educação básica brasileira. Para o primeiro momento, esse tempo não foi possível. Foi necessário reagir de forma emergencial. No entanto, passado o impacto inicial, é preciso buscar novos currículos educacionais e uma formação ao mesmo tempo polivalente e diversificada de professores para a nova etapa que está por vir, seja a continuidade do ensino remoto, seja a transição para o ensino híbrido (MARQUES, 2020; SAMPAIO, 2020).

3) Recebimento de chips para facilitar o processo de acesso à internet $\mathrm{e}$ consequentemente aos conteúdos ministrados pelos docentes.

O campus foco da análise dessa produção está localizado no interior do estado, a maioria dos estudantes reside na zona rural, assim, o acesso à internet de qualidade para o ensino remoto planejado se materializa como um desafio. É o que confirma a pesquisa realizada pela Pró-Reitoria de Ensino, visando a conhecer a situação da conectividade dos estudantes do IFCE, "observou-se que cerca de $34 \%$ dos estudantes possuem acesso à internet" (RESOLUÇÃO 706). Como resposta, o IFCE disponibilizou a distribuição de Chips, conforme os critérios de elegibilidade estabelecidos na Portaria 706. 


\section{REVISTA DE ADMINISTRAÇÃO EDUCACIONAL}

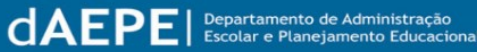

A distribuição dos chips colaborou para a melhoria do acesso ao processo de ensino e aprendizagem nesse período de aulas remotas, mas não sanou todas as dificuldades. No que se refere aos pontos negativos estão:

1) as dificuldades de conectividades, conforme revelado nos parágrafos anteriores. Mesmo com o acesso aos chips que a instituição distribuiu.

2) O excesso de atividades e os prazos para a entrega também aparecem como desafio para o cumprimento do processo uma vez que o calendário está mais reduzido.

Segundo os normativos que orientaram o IFCE, neste período cada aula deveria obrigatoriamente conter uma atividade que contabilizaria presença. Portanto, é preciso considerar que há um limite entre potencializar o aprendizado e sobrecarregar o estudante com exercícios excessivos, e que certamente ele não teria, caso o ensino fosse presencial. Esse ponto tem se revelado de difícil execução, pois os prazos parecem não ser suficientes para o cumprimento de tantas atividades necessárias, como a carga de vídeos, materiais para leitura e atividades de outras matérias.

Como resultado, os docentes acabam por ampliar os prazos de entrega, sobrepondo à aula seguinte, gerando um acúmulo de conteúdo e consequentemente a diminuição do rendimento do estudante. Tal fato é reflexo das orientações oficiais que por mais que estejam apoiadas na justificativa de garantia do direito à educação, acabam reduzindo as soluções e estratégias pedagógicas no contexto da pandemia à entrega de atividades, principalmente no que diz respeito aos estudantes com dificuldade e/ou sem acesso à internet. Dessa forma, é deixado de lado todos os outros aspectos ligados à prática educativa, tais como a mediação, socialização e interação. (SANTOS; LIMA;SOUSA, 2020).

Assim, essa questão das atividades gera dificuldades tanto para o professor que esbarra no desafio de corrigir e alimentar o sistema acadêmico no prazo, como para o estudante que se vê diante do excesso de atividades e parece lidar com o processo de forma mais mecânica, preocupado em cumprir a atividade, do que de fato aprender os conteúdos relacionados.

\section{Considerações finais}

Revista Administração Educacional - CE - UFPE Recife-PE, V.12 N. 1 p. 53-71, jan./jun. 2021 


\section{REVISTA DE ADMINISTRAÇÃO EDUCACIONAL}

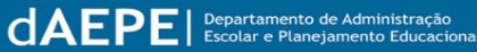

No final do primeiro trimestre de 2020, os primeiros casos de Covid-19 foram registrados no Brasil. No estado Ceará, nesse período, os primeiros decretos relacionados ao fechamento, dentre outros setores, das instituições educacionais, entraram em vigor. No IFCE, um comitê para acompanhamento desse processo foi montado e decidiu pela suspensão das aulas presenciais ainda em março.

Como resposta ao processo de isolamento social imposto pelo quadro de agravamento da situação da pandemia que se instalou no estado nos meses seguintes, o ensino remoto foi adotado. O IFCE tomou suas decisões com base nos instrumentos legais nacionais e estaduais e que assim, como os normativos da instituição, apresentaram dificuldade de estabelecer uma estratégia coesa para o enfrentamento da situação vivenciada.

Os normativos analisados revelam que no primeiro momento de suspensão do calendário, o Instituto demorou a tomar a decisão de suspensão por tempo indeterminado, optando por um processo de renovação semana a semana, fato que causou insegurança e imprecisão para a comunidade acadêmica. Por outro lado, é importante dizer que os normativos apresentam orientações detalhadas sobre como o processo deve ocorrer, desde a questão do direito de imagem, até a forma como a frequência deve ser contabilizada.

Ressalta-se a importância das reuniões de formação e orientação propostas pelo instituto, com o intuito de colaborar minimamente com o processo de adaptação dos docentes a essa nova realidade. Mas é preciso destacar que o processo seguiu desafiante para os docentes, que precisariam de mais tempo para adaptação e formação, uma vez que o uso das ferramentas adotadas para o ensino remoto não fazia parte do cotidiano da maioria dos professores.

Apesar das limitações apresentadas pelos docentes nesse sentido, a empatia e o esforço dos professores foi um dos destaques positivos dos estudantes, no que se refere à realização do ensino remoto. A flexibilidade proporcionada pelas aulas síncronas e assíncronas também foi um ponto positivo. Esse aspecto avaliado pelos estudantes pode indicar a necessidade de reflexões em relação às possibilidades que se desenham e que podem prosseguir mesmo em um futuro em que as aulas presenciais retornem.

O suporte fornecido pela instituição no que se refere à distribuição dos chips de 


\section{REVISTA DE ADMINISTRAÇÃO EDUCACIONAL}

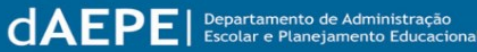

acesso à internet é um benefício que merece ser mantido para além do período pandêmico. Essa estratégia colabora para a redução de desigualdade e promove a democratização do acesso à informação. No entanto, nota-se que, apesar dos avanços que esse elemento impulsionou, ainda há um longo percurso para garantir que, de fato, os estudantes da instituição, em suas diferentes localidades e com suas diversas dificuldades, possam realmente ter o acesso e a qualidade desse processo garantido.

Além das dificuldades de acesso à internet, um ponto negativo destacado pelos estudantes foi o excesso de atividades que precisam ser realizadas em curto prazo, uma vez que o calendário foi reduzido.

É necessário que, após oito meses percorridos desde o início da suspensão do calendário em função da pandemia e cinco meses de ensino remoto no campi analisado na instituição em questão, se reflita sobre como esse processo se deu, o que foi positivo e o que precisa ser reavaliado. Portanto, é preciso que se pensem nos próximos passos e em como esse trabalho deve acontecer, seja por meio do ensino remoto, ou pelo ensino híbrido. A vida das pessoas é, e vai continuar sendo o mais importante, a pandemia não acabou, e está distante disso. É preciso ter responsabilidade e direcionar as decisões de 2021 de modo que seja priorizado a vida das pessoas, para que assim possamos avançar para uma proposta de ensino mais democrática.

\section{Referências}

APPENZELLE, S.; MENEZES; F. H.; SANTOS, G. G.; PADILHA, R. F.; GRAÇA, H. S.; BRAGANÇA, J. F. Novos Tempos, Novos Desafios: Estratégias para Equidade de Acesso ao Ensino Remoto Emergencial. Rev. bras. educ. med. vol.44 supl.1 Brasília 2020 Epub Oct 02 , 2020.Disponível em:https://www.scielo.br/scielo.php?script=sci arttext\&pid=S0100-55022020000500201. Acesso em: 30 de set. de 2020.

BEHAN, P. O Ensino Remoto Emergencial e a Educação a Distância. Disponível em:https://www.ufrgs.br/coronavirus/base/artigo-o-ensino-remoto-emergencial-e-aeducacao-a-distancia/. Acesso em: 22 de out. de 2020.

BRASIL. Ministério da Educação. Portaria No 343 de 17 de março de 2020. Disponível em:https://www.in.gov.br/en/web/dou/-/portaria-n-343-de-17-de-marco-de-2020248564376. Acesso em: 26 de nov. de 2020. 
. Ministério da Educação. Diretrizes Curriculares Nacionais Gerais da Educação Básica. Brasília: MEC, SEB, DICEI, 2013. Disponível em:http://portal.mec.gov.br/index.php?option=com docman\&view $=$ download\&alias $=1344$ 8-diretrizes-curiculares-nacionais-2013-pdf\&Itemid=30192. Acesso em: 10 de out. 2020.

CEARÁ. Decreto $\mathbf{N}^{\mathbf{3}} \mathbf{3 3 . 5 7 4}$ de 05 de maio de 2020. Disponível em:https://www.cge.ce.gov.br/wp-content/uploads/sites/20/2020/05/DECRETON\%C2\%BA33.574-de-05-de-maio-de-2020...pdf. Acesso em: 26 de nov. de 2020.

Decreto $\mathbf{N}^{\mathbf{0}} \mathbf{3 3 . 5 1 0}$ de 16 de março de 2020. Disponível em:https://www.legisweb.com.br/legislacao/?id=390721\#: :text=Decreta $\% 3 \mathrm{~A}$, coronav\%C 3\%ADrus\%20(COVID\%2D19). Acesso em: 26 de nov. de 2020.

GIL, A. C. Como elaborar projetos de pesquisa. 4. ed. São Paulo: Atlas, 2008.

IFCE. Boletim de Serviços. Disponível em: <https://ifce.edu.br/instituto/documentosinstitucionais/boletim-de-servicos>. Acesso em: 01 de outubro de 2020.

\section{IFCE em números. Disponível em:}

https://ifceemnumeros.ifce.edu.br/matriculados/>. Acesso em: 30 de dez. de 2020.

Regulamento da Organização Didática - ROD, Fortaleza, 2015. Disponível em $<$ https://ifce.edu.br/espaco-estudante/regulamento-de-ordem-didatica/2016-07-08-rodrevisao-aprovada-consup-13jun2016-v30.pdf> Acesso em: 01 de out. de 2020.

MARQUES, R. A ressignificação da educação e o processo de ensino e aprendizagem no contexto de pandemia da COVID-19. Boletim de Conjuntura (BOCA), vol. 3, n. 7, 2020. Disponível em: https://revista.ufrr.br/boca/article/view/RiberoJunior. Acesso em: 02 de out. de 2020.

SAMPAIO, R.M. Práticas de ensino e letramentos em tempos de pandemia da COVID19. Research, Society and Development, vol. 9, n. 7, 2020. Disponível em: https://www.researchgate.net/publication/341828320 Praticas de ensino e letramentos e m tempos de pandemia da COVID-19. Acesso em: 28 de out. de 2020.

SANTOS, E. EAD, palavra proibida. Educação online, pouca gente sabe o que é. Ensino remoto, o que temos. Revista Docência e Cibercultura, 2020, Disponível em: https://www.e-publicacoes.uerj.br/index.php/re-doc/announcement/view/1119. Acesso em: 08 de out de 2020.

SANTOS, E.; LIMA, I. S.; SOUSA, N. J. "Da noite para o dia" o ensino remoto: (re) invenções de professores durante a pandemia. Revista Brasileira de Pesquisa (Auto) Biográfica, Salvador, v. 05, n. 16, p. 1632-1648, Edição Especial, 2020. Disponível em: https://www.revistas.uneb.br/index.php/rbpab/article/view/9178. Acesso em 05 de jan. de 2020. 


\section{REVISTA DE ADMINISTRAÇÃO EDUCACIONAL}

\section{ISSN -2359-1382}

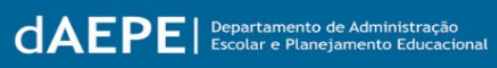

YIN, R. K. Estudo de caso: Planejamento e Métodos. $3^{\text {a }}$ edição. Porto Alegre: Bookman, 2005.

Recebido em:30-11-2020

Aceito em: 20-05-2021

Revista Administração Educacional - CE - UFPE Recife-PE, V.12 N. 1 p. 53-71, jan./jun. 2021 (c) 